\title{
Upper gastrointestinal hemorrhage re-bleeding risk according to the Glasgow-Blatchford scale: a triage tool
}

\section{Miroslava Olivarec-Bonilla, ${ }^{1}$ Anaidt M. García-Montano ${ }^{1}$ and Armando Herrera-Arellano ${ }^{2 *}$}

${ }^{1}$ Adult Emergency Department, No. 1 Regional General Hospital, Instituto Mexicano del Seguro Social, Cuernavaca, Morelos; ${ }^{2}$ Faculty of Medicine, Universidad Autónoma del Estado de Morelos, Cuernavaca, Morelos. Mexico

\begin{abstract}
Introduction: The Glasgow-Blatchford scale (GBS) classifies the risk of re-bleeding after upper gastrointestinal bleeding (UGIB) using clinical data, whereas the Forrest and Dagradi scales do it by endoscopy. Objective: To assess GBS's ability to identify re-bleeding risk within 30 days of an UGIB, using endoscopy as the gold standard for comparison. Method: 129 medical records of patients with UGIB and endoscopy were analyzed. The Glasgow-Blatchford, Forrest and Dagradi scales were quantified; sensitivity, specificity and area under the ROC curve (AUC-ROC) of GBS-reported re-bleeding risk were calculated. Results: GBS identified 53 patients with low re-bleeding risk (41.09\%) and 76 with high risk (58.91\%). Endoscopy identified 107 patients with non-variceal bleeding (82.94\%): 98 with low risk (89.9\%) and 11 with high risk (10.09\%); in addition, it identified 22 patients with variceal hemorrhage (17.05\%): 12 with low risk (54.54\%) and 10 with high risk (45.45\%). GBS showed a sensitivity of 0.857 , specificity of 0.462 and an AUC-ROC of 0.660 . Conclusions: GBS is simple, objective and useful to identify the risk of re-bleeding after UGIB; it is suggested as a triage tool in the emergency department.
\end{abstract}

KEY WORDS: Upper gastrointestinal hemorrhage. Re-bleeding risk. Endoscopy. Glasgow-Blatchford scale. Forrest scale. Dagradi scale.

\section{Riesgo de resangrado en hemorragia digestiva alta según la escala de Glasgow- Blatchford: herramienta de triaje}

\section{Resumen}

Introducción: Con la escala de Glasgow-Blatchford (EG-B) se califica mediante datos clínicos, el riesgo de resangrado después de hemorragia del tubo digestivo alto (HTDA); y con las escalas de Forrest y Dagradi, mediante endoscopia. Objetivo: Evaluar la capacidad de la EG-B para identificar riesgo de resangrado a 30 días después de una HTDA; el estándar de oro de comparación fue la endoscopia. Método: Se analizaron 129 expedientes de pacientes con HTDA y endoscopia. Se cuantificaron las escalas de Glasgow-Blatchford, Forrest y Dagradi; se calculó sensibilidad, especificidad y área bajo la curva ROC (ABC-ROC) del riesgo de resangrado reportado por EG-B. Resultados: La EG-B identificó a 53 pacientes con riesgo bajo de resangrado (41.09\%) y 76 con riesgo alto (58.91\%). Con la endoscopia se identificó a 107 pacientes con hemorragia no variceal (82.94\%), 98 con riesgo bajo (89.9\%) y 11 con riesgo alto (10.09\%); además, 22 pacientes con hemorragia variceal (17.05\%), 12 con riesgo bajo (54.54\%) y 10 con riesgo alto (45.45\%). La EG-B mostró sensibilidad de 0.857 , especificidad de 0.462 y ABC-ROC de 0.660. Conclusiones: La EG-B es sencilla, objetiva y útil para identificar riesgo de resangrado después de HTDA; se sugiere como herramienta de triaje en urgencias.

PALABRAS CLAVE: Hemorragia digestiva alta. Riesgo de resangrado. Endoscopia. Escala de Glasgow-Blatchford. Escala de Forrest. Escala de Dagradi.

Correspondence:

*Armando Herrera-Arellano

E-mail: armandoha_mx@yahoo.com.mx
Gac Med Mex. 2020;156:493-498

Contents available at PubMed

www.gacetamedicademexico.com

0016-3813/@ 2020 Academia Nacional de Medicina de México, A.C.. Published by Permanyer. This is an open access article under the CC BY-NC-ND license (http://creativecommons.org/licenses/by-nc-nd/4.0/). 


\section{Introduction}

Upper gastrointestinal bleeding (UGIB) is a common reason for admission to emergency departments; it is defined as gastrointestinal bleeding above the angle of Treitz, non-variceal and variceal in origin. Up to $16.5 \%$ of re-bleeding has been observed within the first 30 days after hospital discharge, ${ }^{1}$ and it requires up to 133,368 hospitalization days per year, with significant economic overburden., ${ }^{2,3}$ In Mexico, UGIB mortality ranges between 3.3 and $6 \%$, and esophageal varices are the most common cause; ${ }^{4-6}$ in other countries, peptic acid disease is the main cause. ${ }^{7,8}$

UGIB risk is staged with clinical and endoscopic parameters that guide the need for blood transfusion or surgery, as well as the risk of mortality, relapse or bleeding persistence at 30 days. ${ }^{9}$ Prognostic scales classify 30-day re-bleeding risk as low and high. The Glasgow-Blatchford scale (GBS) does not require endoscopic studies and is based on clinical and laboratory data; in addition, it stratifies the need for urgent diagnostic and therapeutic procedures., ${ }^{10-12}$ Patients classified with GBS at low risk of re-bleeding can be safely treated on an outpatient basis, and in those evaluated with high risk, endoscopy should be practiced, preferably within the first 12 hours. ${ }^{13}$

Since endoscopy depends on availability of the resource, triage with scales allows reducing hospital admissions in low-risk patients, as well as prolonged stay. ${ }^{14}$ To predict re-bleeding and the need for endoscopic treatment, transfusion or surgery, GBS is as useful as Rockall post-endoscopy and better than Rockall pre-endoscopy scales. ${ }^{15-19}$ In GBS, the $\leq 2$ cutoff point is the best predictor of low re-bleeding risk and patient safe discharge. ${ }^{19-21}$

Endoscopic scales identify 30-day re-bleeding risk with higher certainty. In peptic ulcer, the Forrest scale assigns the IA, IB, IIA and IIB categories to high risk, and IIC and III categories to low risk, ${ }^{22,23}$ while in esophageal varices, the Dagradi scale identifies six grades, out of which IV, V and VI indicate high risk. ${ }^{24-26}$ Even when there are several validated scales to identify re-bleeding risk after UGIB, they are only applied in $19.4 \%$ of cases. ${ }^{10,26,27}$

The purpose of the research herein presented was to identify the sensitivity, specificity and area under the ROC curve (AUC-ROC) of GBS for 30-day re-bleeding risk in patients with UGIB; the gold standard was endoscopy-determined risk.

\section{Method}

Cross-sectional, analytical, observational study, where medical records of men and women with age equal to or greater than 18 years, admitted during 2016 to the Emergency Department of Regional General Hospital no. 1 of the Mexican Institute of Social Security in Cuernavaca, Morelos, with UGIB of variceal and non-variceal origin, confirmed by endoscopy within 24 hours after admission, were included. Records with incomplete information for GBS staging, with upper digestive cancer diagnosis, hemorrhagic diseases, Barrett's esophagus, anticoagulant treatment and those corresponding to cases that came from another hospital were excluded. The variables that identified 30-day re-bleeding risk were the following:

- GBS: low risk, $\leq 2$ points, and high risk, $\geq 3$ points.

- Forrest endoscopic scale to assess non-variceal UGIB: low risk, classes IIC and III; high risk, classes IA, IB, IIA and IIB.

- Dagradi endoscopic scale for variceal UGIB: low risk, classes I to III; high risk classes IV to VI. ${ }^{27,28}$

Non-probability sampling was used, and the sample consisted of all records of patients with UGIB who met the selection criteria during 2016. For data analysis, descriptive statistics were used; in addition, sensitivity, specificity, positive and negative predictive values, as well as the AUC-ROC of re-bleeding risk indicated by GBS, whose reference parameter was endoscopic risk, were calculated. The analysis was carried out with the Stata program, version 13 . The local research committee of the hospital approved the protocol with registration number R-2017-1701-15.

\section{Results}

During 2016, no. 1 Regional General Hospital had 19,111 emergency department visits of patients older than 16 years, and 390 patients with UGIB were admitted, which represented 20.4 UGIB cases per 1000 visits per year. With the review of records, 154 patients with UGIB and endoscopy within the first 24 hours (39.4\%) were identified; in 25, inclusion criteria were not met. Due to the above, the data analysis included 129 cases, which corresponded to $33.1 \%$ of total UGIB patients admitted in 2016.

Males predominated in the sample, (52\%) and mean age was $63.4 \pm 15.86$ years; main previous conditions related to UGIB were chronic use of non-steroidal anti-inflammatory drugs (66.7 \%), liver 
Table 1. Comparison of the re-bleeding risk groups identified with Glasgow-Blatchford scale

\begin{tabular}{|c|c|c|c|c|c|}
\hline \multirow[t]{2}{*}{ Variable } & \multicolumn{2}{|c|}{ Low risk* $(n=53)$} & \multicolumn{2}{|c|}{ High risk** $(n=76)$} & \multirow{2}{*}{$\frac{\text { Student's }}{\text { P }}$} \\
\hline & Mean & SD & Mean & SD & \\
\hline Age & 62.94 & 16.42 & 63.78 & 15.55 & 0.76 \\
\hline Heart rate (beats/min) & 77.79 & 7.86 & 88.51 & 15.80 & 0.0001 \\
\hline $\mathrm{SBP}(\mathrm{mmHg})$ & 118.07 & 4.84 & 102.15 & 12.22 & 0.001 \\
\hline $\mathrm{DBP}(\mathrm{mmHg})$ & 74.52 & 10.34 & 68.47 & 9.72 & 0.0009 \\
\hline Urea (mg/dL) & 22.22 & 12.79 & 55.79 & 28.29 & 0.0001 \\
\hline $\begin{array}{l}\text { Hemoglobin }(\mathrm{g} / \mathrm{dL}) \\
\text { Males }(\mathrm{g} / \mathrm{dL}) \\
\text { Females }\end{array}$ & $\begin{array}{l}13.12 \\
13.30 \\
13.00\end{array}$ & $\begin{array}{l}0.66 \\
0.69 \\
0.62\end{array}$ & $\begin{array}{l}11.63 \\
11.69 \\
11.54\end{array}$ & $\begin{array}{l}1.32 \\
1.14 \\
1.57\end{array}$ & $\begin{array}{l}0.0001 \\
0.0001 \\
0.0001\end{array}$ \\
\hline $\begin{array}{l}\text { GBS (points) } \\
\text { Non-variceal UGIB } \\
\text { Variceal UGIB }\end{array}$ & $\begin{array}{c}1.22 \\
1.22 \\
2\end{array}$ & $\begin{array}{c}0.92 \\
0.92 \\
-\end{array}$ & $\begin{array}{c}7.30 \\
6.63 \\
9.3\end{array}$ & $\begin{array}{l}3.26 \\
2.91 \\
4.21\end{array}$ & $\begin{array}{c}0.0001 \\
0.0001 \\
N / A\end{array}$ \\
\hline
\end{tabular}

disease $(38.7 \%)$ and alcoholism (32.03\%). Other comorbidities included arthropathy $(27.91 \%)$, hypertension $(27.13 \%)$, chronic kidney disease $(12.4 \%)$ and heart failure $(3.88 \%)$. Predominant symptoms were hematemesis $(92.2 \%)$ and melena $(46.5 \%)$.

With GBS, a mean of $5.04 \pm 3.96$ points was obtained and 53 patients with low re-bleeding risk $(41.09 \%)$ and 76 with high risk $(58.91 \%)$ were identified. Table 1 describes the averages of the variables that make up GBS according to re-bleeding risk, as well as the score obtained in the cases with non-variceal and variceal UGIB. Only one patient with variceal UGIB was classified at low risk with GBS. Except for blood pressure and hemoglobin, significant differences in favor of the high-risk group were observed in most variables.

Endoscopy identified 107 cases with non-variceal bleeding (82.94\%), 20 with variceal bleeding (15.5\%) and two with mixed bleeding (1.55\%). Thus, the analysis included 109 non-variceal bleeding diagnoses and 22 of variceal origin. In patients with non-variceal UGIB, 84 with gastric ulcer (77.06\%) and 25 with erosive gastritis $(22.94 \%)$ were identified; with the Forrest scale, 98 cases with low re-bleeding risk $(89.9 \%)$ and 11 with high risk (10.09\%) were identified. In addition, with the Dagradi scale, 12 cases with low re-bleeding risk $(54.5 \%)$ and 10 with high risk $(45.45 \%)$ were identified among the variceal UGIB cases (Table 2).

Table 3 describes GBS sensitivity and specificity to identify 30-day re-bleeding risk taking endoscopic risk as reference; total sample data are indicated, as well as those of non-variceal and variceal UGIB groups. Sensitivity showed values ranging between 0.818 and 0.900; the highest corresponded to variceal UGIB. Specificity in all three groups was low (between 0 and 0.51 ). It should be noted that the only case of variceal bleeding classified as low risk by GBS turned out to be false negative and, thus, specificity in this group was zero. As for AUC-ROC, the best results were observed in the non-variceal bleeding group $(0.664)$ and in the entire study population (0.660) (Figs. 1-3). There were no deaths during emergency department stay in the sample.

\section{Discussion}

GBS has been systematically used in patients with UGIB as the best predictor of 30-day re-bleeding, of the need for emergency endoscopy, endoscopic intervention and death. ${ }^{15,17-19}$ Consequently, in the consensus for the management of patients with non-variceal UGIB, stratifying the risk of re-bleeding and mortality with already validated scales, performing endoscopy within the first 24 hours in most patients and discharging cases classified by clinical or endoscopic examination with low re-bleeding risk is recommended. ${ }^{9}$

To the best of our knowledge, there are only two publications about UGIB patients admitted to emergency departments of Mexican hospitals; only in one were prognostic scales used. ${ }^{4,25}$ This indicates that validated scales to assign risk of re-bleeding or death in patients with UGIB are not routinely applied in most 
Table 2. Endoscopy-based re-bleeding risk classification in patients with UGIB, according to its origin: non-variceal by means of Forrest scale and variceal using the Dagradi scale

\begin{tabular}{|c|c|c|c|c|}
\hline Forrest Scale & Risk & Frequency & $(\%)$ & Cumulative (\%) \\
\hline $\begin{array}{l}\text { Active bleeding } \\
\text { IA } \\
\text { IB }\end{array}$ & $\begin{array}{l}\text { High } \\
\text { High }\end{array}$ & $\begin{array}{l}2 \\
6\end{array}$ & $\begin{array}{l}1.83 \\
5.50\end{array}$ & $\begin{array}{l}1.83 \\
7.33\end{array}$ \\
\hline $\begin{array}{l}\text { Recent bleeding } \\
\text { IIA } \\
\text { IIB } \\
\text { IIC }\end{array}$ & $\begin{array}{l}\text { High } \\
\text { High } \\
\text { Low }\end{array}$ & $\begin{array}{c}2 \\
1 \\
11\end{array}$ & $\begin{array}{c}1.83 \\
0.92 \\
10.10\end{array}$ & $\begin{array}{c}9.16 \\
10.08 \\
20.18\end{array}$ \\
\hline $\begin{array}{l}\text { No bleeding } \\
\text { III } \\
\text { Total }\end{array}$ & Low & $\begin{array}{c}87 \\
109\end{array}$ & $\begin{array}{l}79.81 \\
99.99\end{array}$ & 99.99 \\
\hline Dagradi scale & Risk & Frequency & $(\%)$ & Cumulative (\%) \\
\hline I & Low & 3 & 13.64 & 13.64 \\
\hline$\|$ & Low & 1 & 4.54 & 18.18 \\
\hline III & Low & 8 & 40.91 & 59.09 \\
\hline IV & High & 0 & 0.00 & 59.09 \\
\hline V & High & 6 & 22.72 & 81.81 \\
\hline $\mathrm{VI}$ & High & 4 & 18.18 & 99.99 \\
\hline Total & & 22 & 99.99 & \\
\hline
\end{tabular}

Table 3. GBS diagnostic test values to predict re-bleeding risk in patients with UGIB*

\begin{tabular}{|l|c|c|c|c|c|}
\hline Group & Sensitivity & Specificity & +PV & -PV & AUC-ROC \\
\hline UGIB total sample & 0.857 & 0.462 & 0.236 & 0.943 & 0.660 \\
\hline Non-variceal UGIB & 0.818 & 0.510 & 0.157 & 0.961 & 0.664 \\
\hline Variceal UGIB & 0.900 & 0.00 & 0.428 & 0.00 & 0.500
\end{tabular}

${ }^{*}$ The gold standard was endoscopy-reported risk. GBS = Glasgow-Blatchford scale, UGIB=upper gastrointestinal bleeding, $+P V=$ positive predictive value, $-\mathrm{PV}=$ negative predictive value, $A \cup C-R O C=$ area under the ROC curve.

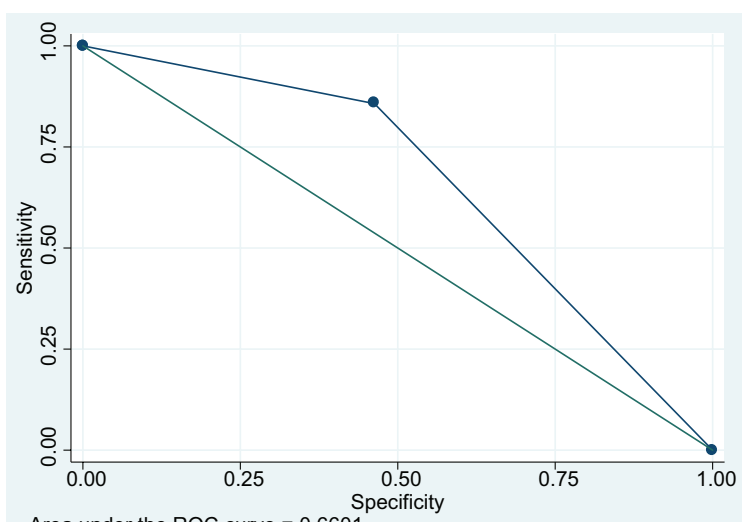

Area under the ROC curve $=0.6601$

Figure 1. Glasgow-Blatchford scale sensitivity, specificity and area under the ROC curve to identify 30-day re-bleeding risk in the entire sample of patients with UGIB; the gold standard was endoscopy-reported risk.

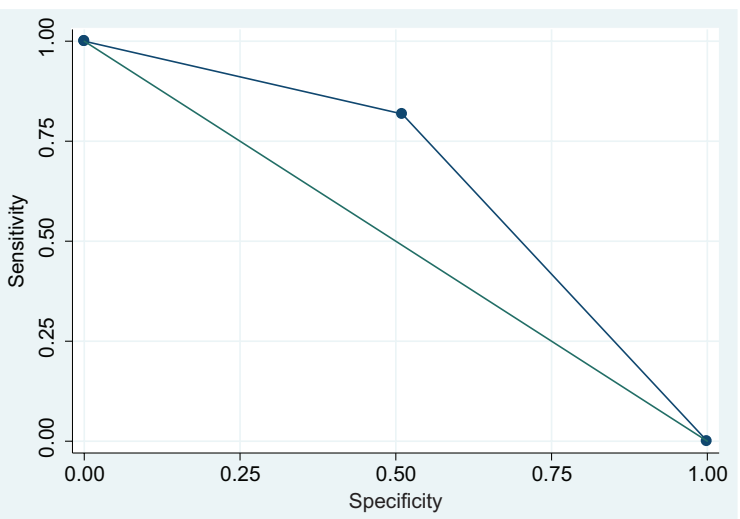

Area under the ROC curve $=0.6642$

Figure 2. Glasgow-Blatchford scale sensitivity, specificity and area under the ROC curve to identify 30-day re-bleeding risk in non-variceal UGIB cases; the gold standard was endoscopy-reported risk. 


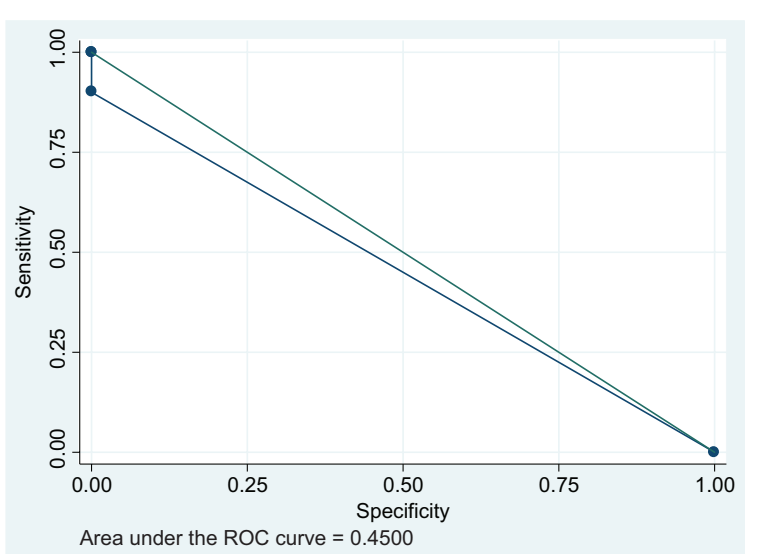

Figure 3. Glasgow-Blatchford scale sensitivity, specificity and area under the ROC curve to identify 30-day re-bleeding risk in cases of variceal UGIB; the gold standard was endoscopy-reported risk.

hospitals in Mexico, even when endoscopy availability is uncertain, which makes it difficult for accurate diagnosis, real risks and UGIB appropriate treatment to be determined. This lack of objective identification of risks originates unnecessary admissions of low-risk patients and, in worst-case scenario, discharges of patients at high risk of poor or fatal outcome.

UGIB is classified, according to its origin, as variceal (mainly associated with portal hypertension) and non-variceal bleeding (mainly associated with peptic acid disease). In our study, males were predominant (52\%), similar to the $51 \%$ reported in another research in Mexico, but different from the $44 \%$ identified in China. ${ }^{4,8}$ Mean age of our patients was $63.4 \pm 15.86$ years, which agrees with the 61.3 years' mean reported by Budimir in 2016 in patients with variceal bleeding, but is higher than the 51.5 years indicated by Wang in 2017 and by Moctezuma Maldonado in 2008. ${ }^{4,8,28}$ On the other hand, since non-variceal UGIB predominated, it was to be expected that most of cases would indicate non-steroidal anti-inflammatory drugs chronic use (67\%) and that hematemesis (92\%) and melena ( $46 \%$ ) would predominate. These data are discordant with those of two studies in Mexico that reported lower percentages of non-steroidal anti-inflammatory drugs use, hematemesis and melena. ${ }^{4,5}$

To assess 30-day re-bleeding risk we considered a value of 2 as the cutoff point in GBS. Based on this, in the sample we identified $41 \%$ of cases with low risk and $59 \%$ with high risk (sensitivity of 0.857 , specificity of 0.462 and AUC-ROC of 0.660 ). This same cutoff point was adopted by Le Jeune (2011) and Recio-Ramírez (2015), who showed that a score $\leq 2$ indicates low probability of adverse clinical outcomes at
30 days, including re-bleeding risk, and recommend it for early discharge ${ }^{19,24}$ However, other authors used a $>1$ score to identify high risk. Thus, Mustafa, in 2015, reported $64.4 \%$ with high risk and $35.6 \%$ with low risk; among the latter, almost half were discharged without any adverse outcome. ${ }^{18}$ In 2016, Motola Kuba indicated that GBS is the best re-bleeding predictor in patients with variceal UGIB due to liver cirrhosis, and that it indicated a higher AUC-ROC than Rockall pre-endoscopy scale; he concluded that routine use of the scale avoids unnecessary admissions or procedures and increases premature and safe discharges. ${ }^{21}$

In 2016, at the hospital where the present investigation was conducted, endoscopy was performed within the first 24 hours in $40 \%$ of all UGIB cases admitted to the Emergency Department, regardless of re-bleeding risk objective evaluation. Various authors refer that endoscopy performed after 24 hours is associated with increased mortality, hospital stay and costs. ${ }^{17}$ In the analyzed sample, $17 \%$ of cases underwent endoscopy within the first 12 hours; in contrast, in another investigation in a private hospital of Mexico City where endoscopy is continuously available, the procedure was reported to have been carried out in $98 \%$ of UGIB cases. ${ }^{4}$ In our analysis, endoscopy identified $83.7 \%$ of non-variceal bleeding cases, similar to other study in Mexico where peptic acid disease (ulcers and erosions) was recorded in $90 \%$ of cases. ${ }^{4}$ However, our percentage of non-variceal UGIB cases differs from those reported in populations of China and Africa, where 52.7 and $51.3 \%$ had this type of UGIB. ${ }^{11,25}$ However, regarding variceal UGIB, the study in China indicates percentages similar to ours (15.1 and $17 \%$ ). ${ }^{11}$

In most cases, low re-bleeding risk was determined using endoscopic scales: $89.9 \%$ in non-variceal UGIB and $54.54 \%$ in variceal UGIB; in the latter, the most common finding was grade III esophageal varices (3 to $4 \mathrm{~mm}$ in diameter, prominent and tortuous), followed by IV and V grade (> $5 \mathrm{~mm}$ and with variable red signs, related to high re-bleeding risk).

In our study, GBS showed high sensitivity (0.857) and good specificity $(0.462)$ to predict 30 -day high re-bleeding risk, regardless of bleeding origin (AUC$\mathrm{ROC}=0.660$ ); in addition, it showed high sensitivity to identify high re-bleeding risk in patients with variceal $(0.900)$ and non-variceal UGIB (0.818). The best predictive values were obtained in the entire sample and in non-variceal UGIB (AUC-ROC of 63.5 and $62.5 \%$, respectively). In variceal UGIB, GBS showed no sensitivity because the only case with low risk turned out to be a false negative. 
GBS negative predictive value was high in the entire sample (0.943) and in non-variceal UGIB (0.961) and, therefore, more than $90 \%$ of these patients with UGIB and GBS low risk are expected not to re-bleed within the ensuing month. In these same groups, positive predictive values were low: 0.236 for the entire sample and 0.157 for non-variceal UGIB, which indicates that with a GBS score $\geq 3$ in patients with UGIB there is a 30 -day re-bleeding risk of $23 \%$. In these cases, to confirm UGIB origin and re-bleeding risk, we suggest that endoscopy should be performed within the first 24 hours.

We conclude that GBS is a simple, objective and useful tool to identify 30-day re-bleeding risk in patients with UGIB, regardless of its origin. It is recommended as a valuable triage tool at emergency departments.

\section{Conflicts of interest}

The authors declare that they have no conflicts of interest.

\section{Funding}

The authors did not receive any sponsoring to prepare this article.

\section{Ethical disclosures}

Protection of human and animal subjects. The authors declare that no experiments were performed on humans or animals for this investigation.

Confidentiality of data. The authors declare that no patient data appear in this article.

Right to privacy and informed consent. The authors declare that no patient data appear in this article.

\section{References}

1. Strömdahl M, Helgeson J, Kalaitzakis E. Emergency readmission following acute upper gastrointestinal bleeding. Eur J Gastroenterol Hepatol. 2016;51:1375-1379.

2. Abougergi MS, Peluso H, Saltzman JR. Thirty-day readmission among patients with non-variceal upper gastrointestinal hemorrhage and effects on outcomes. Gastroenterology. 2018;155:38-46.

3. Adam V, Barkun A. Estimates of costs of hospital stay for variceal and nonvariceal upper gastrointestinal bleeding in the United States. Value Health. 2008;11:1-3.

4. Moctezuma-Maldonado U, Almeda-Valdez P, Lizardi-Cervera J, Morán-Consuelos MA, García-Corona $\mathrm{Cl}$. Hemorragia de tubo digestivo alto. Experiencia en el hospital Médica Sur. Rev Invest Med Sur Mex. 2008;15:176-184.

5. Cruz-Guillén AA, Sánchez-Espinosa JR. Presentación sindromatica del sangrado digestivo alto variceal y no-variceal en el servicio de urgencias de un hospital público de segundo nivel del estado de Chiapas. Análisis descriptivo y comparativo con la prevalencia nacional. Med Int Mex. 2013;29:449-457.

6. Miilunpohja S, Jyrkkä J, Kärkkäinen JM, Kastarinen H, Heikkinen M, Paajanen $\mathrm{H}$, et al. Long-term mortality and causes of death in endoscopically verified upper gastrointestinal bleeding: comparison of bleeding patients and population controls. Scand J Gastroenterol. 2017;52:1211-1218.
7. Hreinsson JP, Kalaitzakis E, Gudmundsson S, Björnsson ES. Upper gastrointestinal bleeding: incidence, etiology and outcomes in a population-based setting. Scand J Gastroenterol. 2013;48:439-447.

8. Wang J, Cui Y, Wang J, Chen B, He Y, Chen M. Clinical epidemiological characteristics and change trend of upper gastrointestinal bleeding over the past 15 years. Zhonghua Wei Chang Wai Ke Za Zhi. 2017;20:425-431.

9. Barkun AN, Bardou M, Kuipers EJ, Sung J, Hunt RH, Martel M, et al. International consensus recommendations on the management of patients with nonvariceal upper gastrointestinal bleeding. Ann Intern Med. 2010;152:101-113.

10. Farooq FT, Lee MH, Das A, Dixit R, Wong RCK. Clinical triage decision vs risk scores in predicting the need for endotherapy in upper gastrointestinal bleeding. Am J Emerg Med. 2012;30:129-134.

11. Blanco-Vela $\mathrm{Cl}$, Peláez-Luna M, Hernández-Guerrero $\mathrm{Al}$ Martínez-García CL, Blanco-Velasco G, Zamora-Nava LE, et al. Guías de diagnóstico y manejo endoscópico de la hemorragia de tubo digestivo alto no-variceal. Asociación Mexicana de Endoscopia Gastrointestinal. Endoscopia. 2017;29:173-195.

12. Cai JX, Saltzman JR. Initial assessment, risk stratification, and early management of acute nonvariceal upper gastrointestinal hemorrhage. Gastrointest Endosc Clin N Am. 2018;28:261-275.

13. Jeong N, Kim KS, Jung YS, Kim T, Shin SM. Delayed endoscopy is associated with increased mortality in upper gastrointestinal hemorrhage. Am J Emerg Med. 2019;37:277-280.

14. Bryant RV, Kuo P, Williamson K, Yam C, Schoeman MN, Holloway RH, et al. Performance of the Glasgow-Blatchford score in predicting clinical outcomes and intervention in hospitalized patients with upper GI bleeding. Gastrointest Endosc. 2013;78:576-583.

15. Le Jeune IR, Gordon AL, Farrugia D, Manwani R, Guha IN, James MW Safe discharge of patients with low-risk upper gastrointestinal bleeding (UGIB): can the use of Glasgow-Blatchford Bleeding Score be extended? Acute Med. 2011;10:176-181.

16. Waddell KM, Stanley AJ. Risk assessment scores for patients with upper gastrointestinal bleeding and their use in clinical practice. Hosp Pract (1995). 2015;43:290-298

17. Tang Y, Shen J, Zhang F, Zhou X, Tang Z, You T. Scoring systems used to predict mortality in patients with acute upper gastrointestinal bleeding in the ED. Am J Emerg Med. 2018;36:27-32.

18. Mustafa Z, Cameron A, Clark E, Stanley AJ. Outpatient management of low-risk patients with upper gastrointestinal bleeding: can we safely extend the Glasgow Blatchford Score in clinical practice? Eur J Gastroenterol Hepatol. 2015;27:512-515.

19. Recio-Ramírez JM, Sáchez-Sáchez MP, Peña-Ojeda JA, Fernández-Romero $\mathrm{E}$, Aguilera-Peña M, del-Campo-Molina $\mathrm{E}$, et al. The predictive capacity of the Glasgow-Blatchford score for the risk stratification of upper gastrointestinal bleeding in an emergency department. Rev Esp Enferm Dig. 2015;107:262-267.

20. Sengupta N, Tapper EB, Patwardhan VR, Ketwaroo GA, Thaker AM, Leffler DA, et al. High Glasgow Blatchford Score at admission is associated with recurrent bleeding after discharge for patients hospitalized with upper gastrointestinal bleeding. Endoscopy. 2016;48:9-15.

21. Stanley AJ, Laine L, Dalton HR, Ngu JH, Schultz M, Abazi R, et al. Comparison of risk scoring systems for patients presenting with upper gastrointestinal bleeding: international multicentre prospective study. BMJ. 2017;356:i6432.

22. De Groot NL, van Oijen MG, Kessels K, Hemmink M, Weusten BL, Timmer R, et al. Reassessment of the predictive value of the Forrest classification for peptic ulcer rebleeding and mortality: can classification be simplified? Endoscopy. 2014;46:46-52.

23. Noda H, Ogasawara N, Izawa S, Ozeki T, Yanamoto K, Okaniwa N, et al. Risk factors for bleeding evaluated using the Forrest classification in Japanese patients after endoscopic submucosal dissection for early gastric neoplasm. Eur J Gastroenterol Hepatol. 2015;27:1022-1029.

24. Narváez-Rivera RM, Cortez-Hernández CA, González-González JA, Tamayo-de la Cuesta JL, Zamarripa-Dorsey F, Torre-Delgadillo A, et al. Consenso Mexicano de Hipertensión Portal. Rev Gastroenterol Mex. 2013;78:92-113

25. Motola-Kuba M, Escobedo-Arzate A, Tellez-Avila F, Altamirano J, Aguilar-Olivos N, González-Angulo A, et al. Validation of prognostic scores for clinical outcomes in cirrhotic patients with acute variceal bleeding. Ann Hepatol. 2016;15:895-901.

26. Santiago-Martínez E, Rodríguez-Magallán A. Indicadores clínicos, endoscópicos y de ultrasonido para riesgo de hemorragia variceal en pacientes con cirrosis. Rev Hosp Juarez Mex. 2006;73:44-50.

27. Leiman DA, Mills AM, Shofer FS, Weber AT, Leiman ER, Riff BP, et al. Glasgow Blatchford Score of limited benefit for low-risk urban patients: a mixed methods study. Endosc Int Open. 2017;5:E950-E958.

28. Budimir I, Gradišer M, Nikolić M, Baršić N, Ljubičić N, Kralj D, et al. Glasgow Blatchford, pre-endoscopic Rockall and AIMS65 scores show no difference in predicting rebleeding rate and mortality in variceal bleeding. Scand J Gastroenterol. 2016;51:1375-1379. 